\title{
Monitoring and management of hypertension with obesity in adolescents
}

This article was published in the following Dove Press journal:

Integrated Blood Pressure Control

Number of times this article has been viewed

\section{Bonita Falkner \\ Department of Medicine and Pediatrics, Thomas Jefferson University, Philadelphia, PA, USA}

Correspondence: Bonita Falkner Division of Nephrology, Thomas Jefferson University, 833 Chestnut Street, Suite 700, Philadelphia, PA 19103, USA

Tel +I 2152052857

Fax +I 3155032506

Email bonita.falkner@jefferson.edu

\begin{abstract}
Largely due to the childhood obesity epidemic, there has been an increase in the prevalence of hypertension in children and adolescents. Obesity associated hypertension is the most common hypertension phenotype among adolescents. Approximately $30 \%$ of obese adolescents have elevated blood pressure (BP) or hypertension. Updated definitions of elevated BP and hypertension in adolescents are now similar to definitions of BP status in adults. For adolescents $\geq 13$ years of age, elevated BP is 120 to $129 /<80 \mathrm{~mm} \mathrm{Hg}$. Hypertension, stage 1 , is $\geq 130$ to $139 / 80$ to $89 \mathrm{~mm} \mathrm{Hg}$, and hypertension, stage 2 , is $\geq 140 / 90 \mathrm{~mm} \mathrm{Hg}$. BP measurements over separate clinic visits are necessary to verify the diagnosis of elevated BP or hypertension. Ambulatory BP monitoring, when available, provides confirmatory data on BP status. Causal mechanisms for obesity associated hypertension include increased sympathetic nervous system activity, increased renal sodium retention secondary to insulin resistance/hyperinsulinemia, and obesity mediated inflammation. The primary treatment for obesity associated hypertension is weight reduction with lifestyle changes in diet and physical activity. Although difficult to achieve, even modest weight reduction can be beneficial. The diet should be rich in fruits, vegetables, fiber, and low-fat dairy with reduction in salt intake. When lifestyle changes are insufficient to achieve BP control, pharmacologic therapy is indicated to achieve a goal BP of $<130 / 80 \mathrm{~mm}$ $\mathrm{Hg}$ or $<90$ th percentile, whichever is lower. Regular BP monitoring is necessary for ongoing management of obesity associated hypertension in adolescents.
\end{abstract}

Keywords: adolescents, obesity, blood pressure, hypertension

\section{Introduction}

The increase in prevalence of hypertension among youth over the past few decades has been well documented. This increase in childhood hypertension prevalence is largely a consequence of the childhood obesity epidemic. ${ }^{1-3}$ Based on current estimates, the overall clinical prevalence of hypertension in children and adolescents, based on repeated measurements, is approximately $3.5 \%$, with higher rates among adolescents. ${ }^{4,5}$ Among obese adolescents, the rates are much higher. In a study of blood pressure (BP) and anthropometrics conducted on high school students, the prevalence of elevated BP (prehypertension and hypertension combined) was over $30 \%$ in obese adolescent boys and between $23 \%$ to $30 \%$, depending on ethnicity, in obese adolescent girls. ${ }^{4}$ The greater prevalence of high BP among obese adolescents compared to normal weight children has been confirmed in several studies on different cohorts and populations..$^{6-8}$ Obesity is defined as body mass index (BMI) $\geq 95$ th percentile; and overweight is defined as $>85$ th percentile to $<95$ th percentile. In normal weight children and adolescents there is a consistent positive rela- 
tionship of weight with BP throughout childhood growth and development. However, excess adiposity disrupts this normal relationship. In a cohort of healthy children and adolescents, Tu et al. ${ }^{9}$ demonstrated that the prevalence of elevated BP $(\geq 90$ th percentile) increased by four-fold when BMI exceeded the 85 th percentile. These findings indicate that in addition to obesity, overweight children and adolescents are also at increased risk for elevated BP and hypertension.

The aforementioned studies applied a definition of hypertension and prehypertension (elevated BP) based on the 2004 Fourth Report. ${ }^{10}$ The recent publication of an update of the pediatric clinical practice guidelines (CPG) has modified the definition of hypertension in adolescents. ${ }^{11}$ In this update, the reference tables on normative childhood BP data were revised. Due to the confirmed effect of overweight and obesity on an increase in BP throughout childhood, the new BP tables are based on BP data only from normal weight children and adolescents (BMI $<85$ th percentile). Thus, age, sex, and height adjusted BP levels for the 90th percentile, designating elevated $\mathrm{BP}$, and 95th percentile, designating hypertension, are somewhat lower than the previous normative BP tables. For children less than 13 years of age, the definitions of elevated BP (previously termed "prehypertension") and hypertension remain the same. Elevated BP is defined as average systolic and/or diastolic BP level that is $\geq 90$ th percentile and $<95$ th percentile; and hypertension is defined as average systolic and/or diastolic BP level that is $\geq 95$ th percentile on repeated visits. However, the definition for elevated BP and for hypertension among adolescents beginning at age 13 years is now different. The new BP tables indicate that the 90th percentile for adolescents aged 13 years and older is close to a systolic BP of $120 \mathrm{~mm} \mathrm{Hg}$ and diastolic BP is $<80 \mathrm{~mm} \mathrm{Hg}$; and the 95th percentile for systolic BP at age 13 years is approximately $130 \mathrm{~mm} \mathrm{Hg}$. These BP numbers mirror the threshold BP levels that are used to define elevated BP and hypertension for adults in the new CPG issued by the American College of Cardiology and the American Heart Association. ${ }^{12}$ Therefore, the current definition of BP classification and staging for adolescents $\geq 13$ years of age is as follows: normal BP: $<120 /<80 \mathrm{~mm} \mathrm{Hg}$; elevated BP: 120 to $129 /<80 \mathrm{~mm} \mathrm{Hg}$; hypertension: $\geq 130 / 80$ $\mathrm{mm} \mathrm{Hg}$. Stage 1 hypertension is 130 to $139 / 80$ to $89 \mathrm{~mm} \mathrm{Hg}$; stage 2 hypertension is $\geq 140 / 90 \mathrm{~mm} \mathrm{Hg}$.

These definitions of hypertension and elevated BP in adolescents age 13 years and above are simplified and harmonize with the new adult definitions. ${ }^{11}$ This change should facilitate detection of abnormal BP in adolescents. The change should also improve recognition of obesity associated hypertension in adolescence.

\section{Diagnosis of hypertension in adolescents}

The diagnosis of hypertension in adolescents require repeated BP measurements that are $\geq 130 / 80 \mathrm{~mm} \mathrm{Hg}$. The average of BP measurements in the hypertensive range on three separate clinic visits are generally required for diagnosis of hypertension in children and adolescents, unless the patient is symptomatic. While automated BP measurement devices are commonly used in clinical practices, BP measurement by auscultation is the preferred measurement method to confirm hypertension in children and adolescents. This is because the normative BP data and BP tables are based on auscultated BP measurements. Over the past decade, a substantial body of data and clinical experience have been developed on the use of ambulatory BP monitoring (ABPM) in childhood. ${ }^{13}$ The updated CPG recommends using ABPM to confirm hypertension in adolescents who have repeated elevated BP measurements. ${ }^{11}$ Approximately $25 \%$ of children with elevated clinic BP measurements have white coat hypertension, a condition in which individuals have hypertension by clinic BP measurements but are normotensive on out of office BP measurements. When white coat hypertension is confirmed by ABPM, further diagnostic testing or treatments to lower $\mathrm{BP}$ are not indicated. However, periodic BP monitoring is recommended. Masked hypertension is a clinical condition in which clinic BP measurements are $<95$ th percentile but ambulatory BP measurements are $\geq 95$ th percentile. Masked hypertension has been identified in both children and adolescents. ${ }^{14}$ Obese adolescents are at greater risk for masked hypertension than non-obese adolescents. ${ }^{15}$ Normally there is a BP decrease, or dip, from the awake phase to the sleep phase on ABPM. Obese adolescents are also at greater risk for abnormal nocturnal dipping, where the decrease in BP during the sleep period is $<10 \%$ of the awake period ABPM. ${ }^{16}$ Therefore, ABPM would be useful in evaluating BP status in obese adolescents with elevated BP.

\section{Insulin resistance and metabolic syndrome}

Insulin resistance (the inverse of insulin sensitivity) is generally defined as a decrease in insulin mediated glucose uptake in response to physiological (endogenous) or exogenous insulin. ${ }^{17} \mathrm{~A}$ biologic consequence of impaired insulin mediated glucose uptake is greater insulin secretion, 
or compensatory hyperinsulinemia, to achieve glucose control. The resulting chronic hyperinsulinemia leads to other potential dysregulatory metabolic and physiologic effects including impaired glucose tolerance, and dyslipidemia. While insulin resistance is present in many clinical conditions, insulin resistance is the core abnormality underlying metabolic syndrome, ${ }^{18}$ a condition with heightened risk for diabetes and cardiovascular disease among adults. ${ }^{19,20}$ Because insulin resistance is difficult to quantify clinically, the concept of metabolic syndrome provides a strategy to identify underlying insulin resistance among individuals with multiple cardiovascular/metabolic risk factors. Despite some variation in the exact definition of metabolic syndrome, the usual definition, from the National Cholesterol Education Program Adult Treatment Panel III (ATPIII) ${ }^{21}$ is three of the following five criteria: 1) visceral obesity, based on waist circumference, 2) elevated BP, 3) abnormal glucose tolerance, 4) elevated plasma triglyceride, and 5) low high density lipoprotein (HDL-cholesterol). Using ATPIII criteria modified for children, Cook et al. ${ }^{22}$ examined the prevalence of metabolic syndrome in children from the National Health and Nutrition Examination Survey (NHANES) data periods 1988-1994. Modifications of criteria for children included BP $\geq 90$ th percentile, waist circumference $>95$ th percentile or $\mathrm{BMI} \geq 95$ th percentile, and triglyceride level $\geq 95$ th percentile on childhood reference table. In this study, metabolic syndrome was identified in $4.2 \%$ of children aged 5 to 18 years. However, among obese adolescents, the prevalence was as high as $28.7 \%$. Another study on a cohort of obese children and adolescents found elevated BP ( $\geq 90$ th percentile), confirmed by repeated BP measurement, in $37 \%$ of the cohort. More boys with elevated BP had low HDL-cholesterol compared to boys with normal BP. ${ }^{23}$ Weiss et al. ${ }^{24}$ reported that the prevalence of metabolic syndrome increased with the severity of obesity and reached 50\% among severely obese youth. Obesity is strongly associated with insulin resistance, which is manifest by relative hyperinsulinemia. ${ }^{25}$ Obesity and elevated BP are two criteria of metabolic syndrome. It is also evident that other components of metabolic syndrome are frequently identified among obese adolescents who express the phenotype of obesity with elevated BP. Therefore, it can be clinically useful to screen obese adolescents with elevated BP for plasma lipids and glucose levels.

\section{Mechanisms for obesity associated hypertension}

Various theories have been proposed to explain a causal role for obesity in elevated BP or hypertension. One theory is that hyperinsulinemia, as a consequence of insulin resistance, activates the sympathetic nervous system (SNS) ${ }^{26}$ A potential mechanism for SNS activation could be adipose tissue production of leptin, which is commonly elevated in obese individuals. ${ }^{27,28}$ Further support for heightened SNS activity in obese hypertensive adolescents was developed using data from 24 hour ABPM. Compared to normal weight hypertensive adolescents, obese hypertensive adolescents have higher heart rates and greater variability during ABPM, suggesting a hyperkinetic hemodynamic condition..$^{8,29,30}$ While heightened SNS activity is likely present among obese adolescents, it is not the only pathway involved in the association of obesity with elevated BP.

Dietary sodium has been implicated in the association of excess adiposity and elevated BP in children and adolescents. Rosner et al. ${ }^{3}$ examined childhood BP trends from sequential NHANES data periods 1988 to 2008. These investigators demonstrated a progressive increase in both the BP level and in the prevalence of high BP in children and adolescents. In their analyses the predictors of increasing BP level and prevalence of high BP were higher BMI and waist circumference, and greater dietary sodium intake. In another study on NHANES data Yang et al. ${ }^{31}$ examined sodium intake on 6,000 children and adolescents, of whom 37\% were overweight or obese. The overall average sodium intake was $3.387 \mathrm{mg}$ / day. The cohort was then stratified according to quartiles of sodium intake, and within each quartile participants were grouped as normal weight or overweight/obese. For the entire cohort, the odds ratio (OR) for risk of elevated BP/ hypertension in the highest sodium quartile compared to the lowest quartile was 2.0. However, among the overweight/ obese participants, the adjusted OR for risk of elevated BP/ hypertension in the highest sodium quartile increased to 3.5; $P=0.013$. Results of these recent epidemiologic studies indicate that obese children and adolescents have greater BP sensitivity to sodium intake compared to normal weight children and adolescents.

The relative hyperinsulinemia associated with obesity in children, as well as adults, can contribute to greater BP sensitivity to sodium intake. Both clinical and experimental research demonstrate that insulin upregulates renal tubular sodium transport. Higher circulating plasma insulin levels can augment sodium reabsorption in the distal tubules which would increase BP. This concept is in line with the results of a study by Rocchini et al. ${ }^{32}$ on a sample of obese adolescents with elevated BP. BP was measured in the obese adolescents following 2 weeks on a high salt diet; and BP measurements were obtained again following 2 weeks on a low salt diet. 
There was a significant reduction in BP following the low salt diet indicating BP sensitivity to sodium. A weight reduction intervention was then provided for the obese adolescent participants over several weeks. Following weight reduction efforts, the high and low salt procedures were repeated. Among the obese adolescents without any weight reduction, the BP response from high to low salt procedures were unchanged. Whereas, among obese adolescents who achieved modest weight reduction, there was a reduction in the BP change from high to low salt diet supporting the concept that a decrease in adiposity resulted in a reduction in BP sensitivity to sodium. Despite limitations in the literature on the role of dietary salt and BP in youth, the available evidence support a contribution of high sodium intake on increases BP among children and adolescents who are overweight or obese.

Another theory to explain the obesity-hypertension association in both adolescents and adults is alterations in microvascular function and structure mediated through inflammation. Obesity is associated with elevated levels of pro-inflammatory cytokines, including $\mathrm{C}$-reactive protein (CRP) and interleukin-6 (IL-6). ${ }^{33}$ Similar elevations of these cytokines have been reported in obese adolescents. ${ }^{24,34}$ Obesity is associated with an accumulation of macrophages in adipose tissue, which may contribute to obesity-related inflammation. ${ }^{35}$ Support for a causal role of inflammation in development of hypertension is largely based on experimental studies that focus on endothelial dysfunction. ${ }^{36,37}$ When human vascular endothelial cells are exposed to CRP in vitro, there is a resulting decrease in expression of endothelial nitric oxide synthase with subsequent attenuation of vasodilation responses. ${ }^{38}$ Experimental works have investigated a role of perivascular adipose tissue (PVAT) in the signaling of inflammatory cytokines. Excess PVAT contributes to endothelial dysfunction and increases vascular smooth muscle tone..$^{39,40}$ This concept was investigated by Greenstein et al. ${ }^{41}$ who used PVAT from lean and obese humans. In in vitro experiments, the investigators found that, compared to PVAT from lean individuals, vasodilatory capacity was lost in PVAT from obese subjects; and in the obese tissues there was concurrent expression of mediators of inflammation and oxidative stress. It is plausible that microvascular dysfunction, mediated by PVAT-derived inflammation could contribute to insulin resistance and capillary rarefaction, both of which create a platform for increased vascular resistance and hypertension.

The potential causal mechanisms underlying obesity associated hypertension among adolescents are likely overlapping with possible synergistic action. Despite gaps in complete understanding of fundamental mechanisms, it is clear that obesity is associated with insulin resistance with compensatory hyperinsulinism; and that in adolescence, this condition has many adverse consequences including elevated BP and premature adult onset cardiovascular disease.

\section{Management of adolescents with obesity and elevated BP}

Management of adolescents with elevated BP or suspected hypertension include confirming the BP status, evaluation for other obesity-related risk factors, and interventions to achieve a more optimal BP. For elevated BP $(120 /<80$ to $129 /<80 \mathrm{~mm} \mathrm{Hg}$ ) or hypertension ( $\geq 130 / 80 \mathrm{~mm} \mathrm{Hg}$ ) measured during a clinical visit, repeated BP measurements are needed at the time of the visit or on subsequent visits when the patient is without symptoms. Repeat BP measurements by auscultation are preferred. ${ }^{11}$ Usually, three separate visits for accurate BP ascertainment are needed to confirm that the average BP is normal, elevated, or hypertensive. Due to the known prevalence of white coat hypertension, ABPM is now recommended to confirm the BP status. ABPM is also informative for obese adolescents who have greater risk for masked hypertension. ${ }^{15}$ For adolescents with confirmed elevated BP or hypertension, additional screening for obesityrelated risk factors including plasma lipids and glucose can be informative of overall health status. Detection of dyslipidemia or impaired glucose tolerance would indicate metabolic syndrome which serves to intensify efforts on weight reduction. A sleep history is useful, especially in very obese adolescents, as sleep disordered breathing or obstructive sleep apnea is often associated with hypertension in adolescents. ${ }^{11}$ Further diagnostic studies are generally not necessary during the initial evaluation unless the patient has a history of previous renal disorders, or a family history of chronic kidney disease.

The major intervention in management of hypertension in obese adolescents is weight reduction. Unfortunately, weight reduction is also very difficult to achieve for obese adolescents, as well as for obese adults. Lifestyle interventions that include changes in diet and increasing physical activity are key for weight reduction and, when achieved over a period of time, have been shown to lower BP in children and adolescents. ${ }^{42,43}$ For stage 1 hypertension, lifestyle interventions with BP monitoring should be tried for 6 to 12 months. ${ }^{11}$

The dietary approach to stop hypertension (DASH) diet plan has demonstrated impressive reductions in BP in adults. $^{44,45}$ The DASH diet includes high intake of fruits, vegetables, whole grains, and low-fat dairy along with reductions in sodium intake. A small clinical trial tested the $\mathrm{DASH}$ diet versus routine nutritional counseling $(\mathrm{RC})$ in a 
sample of hypertensive adolescents. Following 3 months on the diets there was significantly greater BP reduction in the DASH diet group compared to the RC group; and this change persisted for 6 months. ${ }^{46}$ The DASH diet is an appropriate style diet to recommend for obese adolescents. Reductions in dietary sodium intake should be incorporated into the DASH diet plan, especially because average sodium intake of adolescents is well above recommended levels of 2,500 mg/ day. To achieve a reduction in sodium intake it is necessary to limit processed, prepared, and "fast" foods; which are food items generally preferred by adolescents.

Physical activity is beneficial in weight reduction efforts and also improves cardiovascular fitness. Any type of exercise is beneficial and can include aerobic training, resistance training or combined training. ${ }^{47}$ Moderate to vigorous physical activity should be encouraged, with a goal of 30 to 60 minutes on at least 5 days a week. For obese adolescents, the increase in physical activity needs to be gradual to avoid injury, and should include activities that are pleasant and sustainable. While most obese adolescents are not competitive athletes, they should not be restricted from participating in organized sports programs. However, it is recommended that athletic participation by adolescents who have stage 2 hypertension have their participation in high-static competitive sports restricted until their BP is controlled with lifestyle modification and/or pharmacologic therapy. ${ }^{48}$

Pharmacologic therapy to lower BP is indicated for hypertensive adolescents when there is insufficient or no response to lifestyle interventions. Drug treatment is also indicated for adolescents with symptomatic hypertension or persistent stage 2 hypertension. Therefore, pharmacologic therapy should be considered earlier than 6 months of lifestyle interventions in obese adolescents with stage 2 hypertension. With stage 2 hypertension, pharmacologic treatment can be considered following 1 to 3 months of lifestyle interventions, but lifestyle interventions should continue in conjunction with drug treatment. Prior to beginning antihypertension medications an echocardiogram should be obtained for assessment of possible target organ damage. A finding of left ventricular hypertrophy $(\mathrm{LVH})$ on echocardiogram is evidence of hypertensive mediated target organ damage and warrants further effort to lower BP. ${ }^{11}$ It should be noted that obesity also contributes to $\mathrm{LVH}$, an effect that is independent of BP. ${ }^{49,50}$ Therefore, both high BP and obesity contribute to $\mathrm{LVH}$, and BP reduction alone may be insufficient to reduce LVH. It is also prudent to consider if there could be an underlying secondary cause of the hypertension, in addition to the obesity. Standard screening would be a renal ultrasound and blood studies including a complete blood count, electrolytes, creatinine, renin, and aldosterone.

Recommendations on antihypertensive drug therapy in children and adolescents were updated in the recent CPG. ${ }^{11}$ Drug treatment should begin with a single agent at the low end of the dosing range. For initial treatment, the preferred choices are angiotensin converting enzyme (ACE-inhibitor), angiotensin receptor blocking (ARB) agent, long-acting calcium channel blocker (CCB), or a thiazide diuretic. The dose can be up-titrated every 2 to 4 weeks, with BP monitoring every 4 to 6 weeks until the BP is normalized $(<130 /<80 \mathrm{~mm}$ $\mathrm{Hg}$ or $<90$ th percentile, whichever is lower on the new BP tables). ${ }^{11}$ If BP response is insufficient at maximum dose of a single agent, a second drug can be added. A thiazide diuretic is generally the preferred second drug choice. For African American adolescents, who may not have a brisk response to ACE-inhibitors, the initial dose could be somewhat higher. If $\mathrm{LVH}$ is present, $\mathrm{ACE}$-inhibitors or ARBs are initial drug choice. However, ACE-inhibitors and ARBs can have teratogenic effects on fetal development and are contraindicated in pregnancy. Adolescent girls with childbearing potential should be counseled on the possible risks of these drugs, and if there is a risk of pregnancy an alternative drug, such as a $\mathrm{CCB}$, should be prescribed. Beta-blocking agents are generally not recommended as initial drug choices in obese adolescents, because many of these drugs have an adverse effect on insulin resistance. If the BP control is not achieved with three drugs, non-compliance should be considered or possibly a missed diagnosis of secondary hypertension. Repeat BP monitoring with ABPM can be useful in these situations. While drug therapy may be necessary to achieve BP control, efforts to reduce excess body weight with lifestyle changes should be continued. If weight loss is achieved, it may become possible to decrease or even withdraw drug therapy. However, even with withdrawal of drug treatment, regular BP monitoring should continue.

\section{Summary}

Hypertension associated with obesity is commonly found in adolescents. Approximately $30 \%$ of adolescents with obesity have elevated BP or hypertension. Overweight and obese adolescents have greater BP sensitivity to dietary salt compared to normal weight adolescents. The relative endogenous hyperinsulinemia associated with obesity contributes to the salt sensitivity. While there are other possible mechanisms that contribute to elevated $\mathrm{BP} /$ hypertension in obese adolescents, the optimal treatment is weight reduction. Although achieving a normal body weight is extremely difficult, even modest 
reductions in weight can be beneficial. Dietary changes with a shift from processed high salt foods to a diet rich in fruits, vegetables, fiber, and low fat dairy along with a reduction in sodium intake are important initial therapy along with an increase in physical activity. If BP reduction by lifestyle change is not achieved, drug therapy can be beneficial in achieving control of BP. Initial BP monitoring, including ABPM is necessary to confirm hypertension status. And when BP control is achieved, BP monitoring should continue to ensure that BP control continues through adolescence.

\section{Disclosure}

The author reports no conflicts of interest in this work.

\section{References}

1. Din-Dzietham R, Liu Y, Bielo MV, Shamsa F. High blood pressure trends in children and adolescents in national surveys, 1963 to 2002. Circulation. 2007;116(13):1488-1496.

2. Munter P, He J, Cutler JA, Wildman RP, Welton PK. Trends in blood pressure among children and adolescents. JAMA. 2004;291(17): 2107-2113.

3. Rosner B, Cook NR, Daniels S, Falkner B. Childhood blood pressure trends and risk factors for high blood pressure: the NHANES experience 1988-2008. Hypertension. 2013;62(2):247-254.

4. McNiece KL, Poffenbarger TS, Turner JL, Franco KD, Sorof JM, Portman RJ. Prevalence of hypertension and pre-hypertension among adolescents. J Pediatr. 2007;150(6):640-644.

5. Hansen ML, Gunn PW, Kaelber DC. Underdiagnosis of hypertension in children and adolescents. JAMA. 2007;298(8):874-879.

6. Falkner B, Gidding SS, Ramirez-Garnica G, Wiltrout SA, West D, Rappaport EB. The relationship of body mass index and blood pressure in primary care pediatric patients. J Pediatr. 2006;148(2):195-200.

7. Schwandt P, Scholze JE, Bertsch T, Leopold E, Haas GM. Blood pressure percentiles in 22,051 German children and adolescents: the PEP family heart study. Am J Hypertens. 2015;28(5):672-679.

8. Sorof J, Daniels S. Obesity hypertension in children: a problem of epidemic proportions. Hypertension. 2002;40(4):441-447.

9. Tu W, Eckert GJ, DiMeglio LA, Yu Z, Jung J, Pratt JH. Intensified effect of adiposity on blood pressure in overweight and obese children. Hypertension. 2011;58(5):818-824.

10. National High Blood Pressure Education Program Working Group on High Blood Pressure in Children and Adolescents. The fourth report on the diagnosis, evaluation, and treatment of high blood pressure in children and adolescents. Pediatrics. 2004;114(2 Suppl 4th Report):555-576.

11. Flynn JT, Kaelber DC, Baker-Smith CM, et al. Clinical practice guideline for screening and management of high blood pressure in children and adolescents. Pediatrics. 2017;140(3).

12. Whelton PK, Carey RM, Aranow WS, et al. 2017 ACC/AHA/AAPA/ ABC/ACPM/AGS/APhA/ASH/ASPC/NMA/PCNA guideline for the prevention, detection, evaluation, and management of high blood pressure in adults: a report of the American College of Cardiology/ American Heart Association Task Force on Clinical Practice Guidelines. Hypertension. Epub 2017, Nov 13.

13. Flynn JT, Daniels S, Hayman LL, et al. Update: ambulatory blood pressure monitoring in children and adolescents. a scientific statement from the American Heart Association. Hypertension. 2014;63(5):1116-1135.

14. Lurbe E, Torro I, Alvarez V, Nawrot T, Paya R, Redon J, Staessen JA. Prevalence, persistence, and clinical significance of masked hypertension in youth. Hypertension. 2005;45(4):493-498.
15. So HK, Yip GW, Choi KC, et al. Association between waist circumference and childhood-masked hypertension: A community-based study. J Paediatr Child Health. 2016;52(4):385-390.

16. Macumber IR, Weiss NS, Halbach SM, Hanevold CD, Flynn JT. The Association of Pediatric Obesity With Nocturnal Non-Dipping on 24-Hour Ambulatory Blood Pressure Monitoring. Am J Hypertens. 2016;29(5): 647-652.

17. Levy-Marchal C, Arslanian S, Cutfield W, et al. Insulin resistance in children: consensus, perspective, and future directions. J Clin Endocrinol Metab. 2010;95(12):5189-5198.

18. DeFronzo RA, Ferrannini E. Insulin resistance. A multifaceted syndrome responsible for NIDDM, obesity, hypertension, dyslipidemia, and atherosclerotic cardiovascular disease. Diabetes Care. 1991;14(3): 173-194.

19. Lakka HM, Laaksonen DE, Lakka TA, Niskanen LK, Kumpusalo E, Tuomilehto J, Salonen JT. The metabolic syndrome and total and cardiovascular disease mortality in middle-aged men. JAMA. 2002;288(21):2709-2716.

20. Meigs JB, Wilson PW, Fox CS, Vasan RS, Nathan DM, Sullivan LM, D'Agostino RB. Body mass index, metabolic syndrome, and risk of type 2 diabetes or cardiovascular disease. J Clin Endocrinol Metab. 2006;91(8):2906-2912.

21. Expert Panel on Detection E, and Treatment of High blood Cholesterol in Adults. Executive Summary of The Third Report of The National Cholesterol Education Program (NCEP) Expert Panel on Detection, Evaluation, And Treatment of High Blood Cholesterol In Adults (Adult Treatment Panel III). JAMA. 2001;285(19):2486-2497.

22. Cook S, Auinger P, Li C, Ford ES. Metabolic syndrome rates in United States adolescents, from the National Health and Nutrition Examination Survey, 1999-2002. J Pediatr. 2008;152(2):165-170.

23. Boyd GS, Koenigsberg J, Falkner B, Gidding S, Hassink S. Effect of obesity and high blood pressure on plasma lipid levels in children and adolescents. Pediatrics. 2005;116(2):442-446.

24. Weiss R, Dziura J, Burgert TS, et al. Obesity and the metabolic syndrome in children and adolescents. N Engl J Med. 2004;350(23):2362-2374.

25. Caprio S. Insulin resistance in childhood obesity. J Pediatr Endocrinol Metab. 2002;15(Suppl 1):487-492.

26. Esler M, Straznicky N, Eikelis N, Masuo K, Lambert G, Lambert E. Mechanisms of sympathetic activation in obesity-related hypertension. Hypertension. 2006;48(5):787-796.

27. DiBona GF. Sympathetic nervous system and hypertension. Hypertension. 2013;61(3):556-560.

28. Lim K, Jackson KL, Sata Y, Head GA. Factors responsible for obesityrelated hypertension. Curr Hypertens Rep. 2017;19(7):53.

29. Litwin M, Simonetti GD, Niemirska A, Ruzicka M, Wühl E, Schaefer F, Feber J. Altered cardiovascular rhythmicity in children with white coat and ambulatory hypertension. Pediatr Res. 2010;67(4):419-423.

30. Niemirska A, Litwin M, Feber J, Jurkiewicz E. Blood pressure rhythmicity and visceral fat in children with hypertension. Hypertension. 2013;62(4):782-788.

31. Yang Q, Zhang Z, Kuklina EV, et al. Sodium intake and blood pressure among US children and adolescents. Pediatrics. 2012;130(4):611-619.

32. Rocchini AP, Key J, Bondie D, et al. The effect of weight loss on the sensitivity of blood pressure to sodium in obese adolescents. $N$ Engl $J$ Med. 1989;321(9):580-585.

33. Lyon CJ, Law RE, Hsueh WA. Minireview: adiposity, inflammation, and atherogenesis. Endocrinology. 2003;144(6):2195-2200.

34. DeLoach S, Keith SW, Gidding SS, Falkner B. Obesity associated inflammation in African American adolescents and adults. Am J Med Sci. 2014;347(5):357-363.

35. Wu H, Ghosh S, Perrard XD, et al. T-cell accumulation and regulated on activation, normal $\mathrm{T}$ cell expressed and secreted upregulation in adipose tissue in obesity. Circulation. 2007;115(8):1029-1038.

36. Guzik TJ, Hoch NE, Brown KA, et al. Role of the T cell in the genesis of angiotensin II induced hypertension and vascular dysfunction. J Exp Med. 2007;204(10):2449-2460. 
37. Madhur MS, Lob HE, McCann LA, Iwakura Y, Blinder Y, Guzik TJ, Harrison DG. Interleukin 17 promotes angiotensin II-induced hypertension and vascular dysfunction. Hypertension. 2010;55(2):500-507.

38. Venugopal SK, Devaraj S, Yuhanna I, Shaul P, Jialal I. Demonstration that C-reactive protein decreases eNOS expression and bioactivity in human aortic endothelial cells. Circulation. 2002;106(12):1439-1441.

39. Houben AJ, Eringa EC, Jonk AM, Serne EH, Smulders YM, Stehouwer CD. Perivascular fat and the microcirculation: relevance to insulin resistance, diabetes, and cardiovascular disease. Curr Cardiovasc Risk Rep. 2012;6(1):80-90.

40. Marchesi C, Ebrahimian T, Angulo O, Paradis P, Schiffrin EL. Endothelial nitric oxide synthase uncoupling and perivascular adipose oxidative stress and inflammation contribute to vascular dysfunction in a rodent model of metabolic syndrome. Hypertension. 2009;54(6):1384-1392.

41. Greenstein AS, Khavandi K, Withers SB, et al. Local inflammation and hypoxia abolish the protective anticontractile properties of perivascular fat in obese patients. Circulation. 2009;119(12):1661-1670.

42. Verduci E, Lassandro C, Giacchero R, Miniello VL, Banderali G, Radae1li G. Change in metabolic profile after 1-year nutritional-behavioral intervention in obese children. Nutrients. 2015;7(12):10089-10099.

43. Lustig RH, Mulligan K, Noworolski SM, et al. Isocaloric fructose restriction and metabolic improvement in children with obesity and metabolic syndrome. Obesity (Silver Spring). 2016;24(2):453-460.

44. Appel LJ, Moore TJ, Obarzanek E, et al. A clinical trial of the effects of dietary patterns on blood pressure. DASH Collaborative Research Group. N Engl J Med. 1997;336(16):1117-1124.
45. Sacks FM, Svetkey LP, Vollmer WM, et al. Effects on blood pressure of reduced dietary sodium and the Dietary Approaches to Stop Hypertension (DASH) diet. DASH-Sodium Collaborative Research Group. N Engl J Med. 2001;344(1):3-10.

46. Couch SC, Saelens BE, Levin L, Dart K, Falciglia G, Daniels SR. The efficacy of a clinic-based behavioral nutrition intervention emphasizing a DASH-type diet for adolescents with elevated blood pressure. J Pediatr. 2008;152(4):494-501.

47. Farpour-Lambert NJ, Aggoun Y, Marchand LM, Martin XE, Herrmann FR, Beghetti M. Physical activity reduces systemic blood pressure and improves early markers of atherosclerosis in pre-pubertal obese children. J Am Coll Cardiol. 2009;54(25):2396-2406.

48. Black HR, Sica D, Ferdinand K, White WB. Eligibility and disqualification recommendations for competitive athletes with cardiovascular abnormalities: Task force 6: hypertension: a scientific statement from the American Heart Association and the American College of Cardiology. J Am Coll Cardiol. 2015;66(21):2393-2397.

49. Crowley DI, Khoury PR, Urbina EM, Ippisch HM, Kimball TR. Cardiovascular impact of the pediatric obesity epidemic: higher left ventricular mass is related to higher body mass index. $J$ Pediatr. 2011;158(5):709-714.e1.

50. Brady TM. The role of obesityin the development of left ventricular hypertrophy among children and adolescents. Curr Hypertens Rep 2016;18(1):3.
Integrated Blood Pressure Control

\section{Publish your work in this journal}

Integrated Blood Pressure Control is an international, peer-reviewed open-access journal focusing on the integrated approach to managing hypertension and risk reduction. Treating the patient and comorbidities together with diet and lifestyle modification and optimizing healthcare resources through a multidisciplinary team approach constitute key

\section{Dovepress}

features of the journal. This journal is indexed on American Chemical Society's Chemical Abstracts Service (CAS). The manuscript management system is completely online and includes a very quick and fair peerreview system, which is all easy to use. Visit http://www.dovepress.com/ testimonials.php to read real quotes from published authors. 